\title{
Perspectives on Functional Red Mold Rice: Functional Ingredients, Production, and Application
}

\author{
Feng Yanli ${ }^{1,2,3,4 *}$ and Yu Xiang ${ }^{1,2,3,4}$ \\ ${ }^{1}$ Hubei Key Laboratory of Edible Wild Plants Conservation and Utilization, Hubei Normal University, Huangshi, China, ${ }^{2}$ Hubei \\ Engineering Research Center of Typical Wild Vegetables Breeding and Comprehensive Utilization Technology, Hubei Normal \\ University, Huangshi, China, ${ }^{3}$ National Demonstration Center for Experimental Biology Education, Hubei Normal University, \\ Huangshi, China, ${ }^{4}$ College of Life Sciences, Hubei Normal University, Huangshi, China
}

\section{OPEN ACCESS}

Edited by: Wanping Chen, Georg-August-University Göttingen, Germany

Reviewed by:

Bo-Bo Zhang,

Shantou University, China Chan Zhang,

Beijing Technology and Business

University, China

Yang Hua,

Tianjin University of Science and Technology, China

${ }^{*}$ Correspondence: Feng Yanli

fengyanli@hbnu.edu.cn

Specialty section:

This article was submitted to

Food Microbiology,

a section of the journal

Frontiers in Microbiology

Received: 16 September 2020

Accepted: 29 October 2020

Published: 25 November 2020

Citation:

Yanli F and Xiang Y (2020)

Perspectives on Functional Red Mold Rice: Functional Ingredients,

Production, and Application.

Front. Microbiol. 11:606959.

doi: 10.3389/fmicb.2020.606959
Monacolin K (MK) is a secondary metabolite of the Monascus species that can inhibit cholesterol synthesis. Functional red mold rice (FRMR) is the fermentation product of Monascus spp., which is rich in MK. FRMR is usually employed to regulate serum cholesterol, especially for hypercholesterolemic patients who refuse statins or face statin intolerance. The present perspective summarized the bioactive components of FRMR and their functions. Subsequently, efficient strategies for FRMR production, future challenges of FRMR application, and possible directions were proposed. This perspective helps to understand the present situation and developmental prospects of FRMR.

Keywords: functional red mold rice, monacolins, functional ingredients, production, application, Monascus spp.

\section{INTRODUCTION}

Red mold rice (RMR), also called red koji or red yeast rice is the fermentation product of Monascus spp. (Farkouh and Baumgärtel, 2019). It is widely used as a colorant, supplement, and starters in the food industry in Asian countries. RMR contains multiple beneficial metabolites, such as Monascus pigments, monacolin $\mathrm{K}(\mathrm{MK})$, and $\gamma$-aminobutyric acid. RMR also contains some enzymes, for instance, protease and amylase (De Backer, 2017; Chen et al., 2019; Jiang et al., 2019). However, a mycotoxin-citrinin produced by Monascus spp. can induce health risks (He et al., 2020b). Nowadays, RMR has three main product types on the market depending on its application, as follows: coloring RMR, brewing RMR, and functional red mold rice (FRMR). Coloring RMR is the RMR with a color value higher than 1,000 U/g according to the National Food Safety Standard of China (GB 1886.19-2015). Brewing RMR is the RMR that possesses strong saccharifying power and esterifying power, which is used as a fermentation starter in the food industry based on the Light Industry Standard of the People's Republic of China (QB/T 5188-2017). FRMR is the RMR with a natural MK of more than $0.4 \%$ according to the Light Industry Standard of the People's Republic of China (QB/T 2847-2007). MK is chemically identical to lovastatin, which is a lipid-lowering drug and shows evident effects on inhibiting 3-hydroxy-3-methylglutaryl-CoA (HMG-CoA) reductase that catalyzes the rate-limiting step of cholesterol biosynthesis (De Backer, 2017; Bruno et al., 2018). Therefore, FRMR is a commonly consumed food supplement by hypercholesterolemia patients, especially for statin-intolerant community (Mazzanti et al., 2017; Xiong et al., 2019).

However, some issues related to FRMR should be taken into consideration. Firstly, MK has a large number of analogs with different lipid-lowering effects and complex conversion relationships (Kimura et al., 1990; Li et al., 2017; Beltrán et al., 2019). For instance, 84 monacolins (MLs) have been monitored in RMR sample (Li et al., 2017). FRMR available from market contains 
different contents of MK and different MLs in each FRMR sample (Dujovne, 2017). Therefore, it is inappropriate to define the functions of FRMR by merely depending on its MK content. Secondly, MK possesses specific active forms and has multiple functions. $\mathrm{MK}$ is an inactive lactone, which needs to be converted into its active $\beta$-hydroxy acid form (MKA) for the lipidlowering activity (Yang and Hwang, 2006). Moreover, some other functions of MLs have also been reported, including promoting bone formation, being an antioxidant, and suppressing cancer cell proliferation (Wong and Rabie, 2008; Kurokawa et al., 2017; Nagabhishek and Madankumar, 2019; del Gaudio et al., 2020). Thirdly, a great number of metabolites besides MLs are available from FRMR. The functions of the beneficial metabolites such as Monascus pigments and $\gamma$-aminobutyric acid should be understood and evaluated, while using FRMR as a food supplement or as an alternative drug to the chemical statins. Meanwhile, the toxic metabolite produced by some Monascus strains, citrinin, should not only be studied but should also be carefully controlled (Farkouh and Baumgärtel, 2019). Furthermore, the side effects of MLs such as myopathies and liver injury need to be evaluated (Mazzanti et al., 2017). For the efficient application of FRMR, MK contents of FRMR should be standardized, and the functions and safety of FRMR need to be evaluated.

To obtain sufficient MK in FRMR, parameters for FRMR production in solid- and liquid-state fermentation such as initial moisture, $\mathrm{pH}$, and nitrogen source have been optimized ( $\mathrm{Hp}$, 2012; Feng et al., 2014; Lin et al., 2017; Huang et al., 2018). Moreover, the screening of Monascus strains with high-MK production has also been carried out (Suh et al., 2007; Wang et al., 2011). Novel substrates have been utilized for FRMR production and enriching its product types, such as Dioscorea, Finger millet, and Saccharina japonica (Lee et al., 2007; Venkateswaran and Vijayalakshmi, 2010; Suraiya et al., 2018). All these strategies head for high-quality FRMR. The natural and environmental-friendly production of FRMR with sufficient MK is also prospected.

In the present perspective, we focus on the MLs in FRMR and their differences with lovastatin; strategies for efficient production of FRMR, the current situation of FRMR application, and the corresponding future directions for a wide application were proposed.

\section{FUNCTIONAL SUBSTANCES IN FRMR}

Monacolins are the main bioactive substances in FRMR. MK was chemically identified as lovastatin and was first isolated from the cultures of Monascus ruber No. 1005 as a hypocholesterolemic agent in 1979 (Endo, 1979). MK is a polyketide compound synthesized by polyketide synthase (PKS) in Monascus spp. MK biosynthetic pathway and gene cluster in Monascus spp. are similar to those of lovastatin from Aspergillus terreus (Zhang et al., 2020). The MK gene cluster including nine genes named mok A-mok I was isolated from the genome of Monascus pilosus, and functions of the genes have been carried out (Chen et al., 2008; Zhang et al., 2017b). Overexpression of key genes (mokC, mokD, mokE, and mokI) in the Monascus purpureus azaphilone polyketide pathway can be used to improve MK production (Zhang et al., 2019).

Monacolins are chemical analogs of MK that share a similar basic skeleton, with difference in the substituent groups. MLs are mainly divided into lactone ring form and free acidic form (Li et al., 2017). At least 84 MLs have been identified, though not all of the MLs have been studied (Li et al., 2017). MLs, for instance, monacolin L, monacolin J, dihydromonacolin L, monacolin X, and compactin, etc., in both the lactone and acid forms have attracted more attention, owing to their high contents in FRMR and their well-known beneficial bioactivities (Endo and Hasumi, 1985; Endo, 1985a,b; Endo et al., 1986; Dhale et al., 2007a,b; Zhu et al., 2012; Hachem et al., 2020). With the progress in research on these compounds, more and more MLs have been isolated and characterized. The structures and functions of MLs O-S, $\alpha, \beta$-dehydromonacolin $S, 3 \alpha$ - hydroxy-3,5-dihydromonacolin $\mathrm{L}$, 3b-hydroxy-3,5-dihydro monacolin L, $\alpha, \beta$-hydromonacolin $\mathrm{Q}$, monacolin T, monacolin U, 6a-O-methyl-4,6-dihydromonacolin $\mathrm{L}$ and 6a-O-ethyl-4,6- dihydromonacolin $\mathrm{L}$ have been explored (Li et al., 2004; Liu et al., 2013; Zhang et al., 2016, 2018a). It is interesting that an unusual aromatic monacolin analog, monacophenyl, was isolated from RMR (Liu et al., 2011). In view of this, one of the most important key points for taking full advantage of FRMR is exploring its functions and side effects.

Besides MLs, other functional substances such as pigments, ergosterol, $\gamma$-aminobutyric acid, and polysaccharides, also play a certain role in the function of FRMR (Wang et al., 2014; Liang et al., 2019). For instance, ergosterol showed remarkable lipid-lowering efficiency. Moreover, three Monascus azaphilone pigments of monascin, monasfluore $\mathrm{B}$, and ankaflavin were discovered as ligands of lipase (Fang et al., 2017; Liang et al., 2019).

\section{FUNCTIONS OF FRMR}

Functional red mold rice is widely consumed as a lipid-lowering product due to it containing MLs. Among the most commonly studied MLs, MK and its dihydro derivatives are the most active compounds for lowering lipid levels (Avula et al., 2014). However, MK exists in the inactive form naturally and undergoes reduction to its $\beta$-hydroxy acid (MKA) active form (Beltrán et al., 2019). MK in the lactone form gets absorbed from the gastrointestinal tract and gets converted into MKA in liver and non-hepatic tissues (Ertürk et al., 2003). In addition, the transformation process of MK into MKA spontaneously occurs at neutral $\mathrm{pH}$, without the participation of gut microbiota. However, the lipid-lowering effect is mediated by the gut microbiota by catabolizing MKA to other compounds (Beltrán et al., 2019). In vitro experiments also indicated that MK could be completely converted into MKA only in alkaline solutions (Yang and Hwang, 2006).

Monacolins are usually obtained by consuming FRMR as a food supplement or from FRMR in combination with other bioactive compounds (Yang and Mousa, 2012; Heinz et al., 2016; D’Addato et al., 2017; Iskandar et al., 2020). An efficient and better tolerance in hypercholesterolemic patients was seen 
when FRMR was combined with other bioactive compounds. For instance, combining FRMR with guggulipid extract, chromium picolinate, berberine, and coenzyme $\mathrm{Q}_{10}$ showed a better tolerance and efficiency (Yang and Mousa, 2012; Di Pierro et al., 2016; Cicero et al., 2017; D’Addato et al., 2017; Stefanutti et al., 2017; Mazza et al., 2018; Formisano et al., 2019; Wang et al., 2019; Iskandar et al., 2020).

Besides the lowering lipid effects, the physiological functions of MLs like promoting bone formation, attenuating arterial thrombosis, and anticancer have also been confirmed (Wong and Rabie, 2008; Tseng et al., 2011; Tien et al., 2016; Xu et al., 2017; Wang et al., 2019). New bone formation in bone defects in vivo and bone cell formation in vitro can be stimulated and increased using RMR extract (Wong and Rabie, 2008). In addition, apoptosis on gastric cancer was induced by MLs and other components by scavenging the mitochondrial reactive oxygen species (Kurokawa et al., 2017). Monacolin X is known to attenuate the cell proliferation, migration, and ROS stressmediated apoptosis in breast cancer cells, which provides a scope for the functional research of MLs (Nagabhishek and Madankumar, 2019). Another important function of FRMR is its strong antioxidant effect, which needs to be taken into consideration (Lee et al., 2009; Mohan-Kumari et al., 2011).

\section{EFFICIENT PRODUCTION OF FRMR}

\section{Optimization for Production of Monacolins}

Optimization of the fermentation parameters for MK production has attracted much interest since its discovery (Tsukahara et al., 2009; Panda et al., 2010; Hp, 2012; Dikshit and Tallapragada, 2016). Liquid state fermentation (LSF) has not yielded constant results and higher production. Therefore, solidstate fermentation (SSF) is gaining an increasing popularity for multiple industrially important products such as pigments, enzymes, and antibiotics, besides MLs. SSF has been widely employed in the industrial production of FRMR, due to its advantages like maximum substrate utilization, better process control, lower chances of contamination, and easy downstream processing (Praveen and Savitha, 2012). Therefore, fermentation parameters of SSF for FRMR production, such as moisture content, fermentation temperature, and inoculum concentration have been studied extensively and discussed herewith. Generally, adjusting the moisture content to $35 \%$ $(w / w)$ and maintaining an environmental humidity at 55 65\% is beneficial for the MK production (Subhagar et al., 2009; Feng et al., 2014). Fermentation temperature is another vital parameter for MK production. The temperature-shift cultivation is more advantageous for the MK production, when compared with the constant temperature fermentation. Monascus spp. are generally cultured at $30^{\circ} \mathrm{C}$ for their growth and at lower temperature such as $25^{\circ} \mathrm{C}$ or even $23^{\circ} \mathrm{C}$ for $\mathrm{MK}$ production (Tsukahara et al., 2009; Lin et al., 2017). In addition, the inoculum concentration also shows an influence on Monascus fermentation and MK production (Subhagar et al., 2009). Appropriate inoculum size starts the fermentation quickly and maintains the fermentation process at a good rate for metabolite production. There is a significant relation between the inoculum size and the spore concentrations of the inoculum, for instance, by adjusting them to $13 \%(v / w)$ and $10^{6} \mathrm{CFU} / \mathrm{ml}$, respectively (Feng et al., 2014). For the speedy growth of Monascus spp. and avoiding contamination by other microorganisms, lactic acid and acetic acid are usually added to adjust the $\mathrm{pH}$ of the fermentation substrates (Xu et al., 2005; Feng et al., 2014). The methods for improving the MK production by Monascus strains have been screened by chemical mutagenesis or genetic engineering technology (Yang et al., 2005b; Suh et al., 2007; Wang et al., 2011). A mutant KU609 with high MK and no citrinin production has been obtained from the wild-strain Monascus isolate number 711 by subjecting to $\gamma$ irradiation (Suh et al., 2007). The binary vector pCAMBIA3300$g p d A-h p h-\operatorname{tr} p C$ with hygromycin B phosphotransferase ( $h p h)$ was constructed and transformed into Monascus albidus 9901 by Agrobacterium tumefaciens-mediated transformation. Two transformants $\mathrm{H} 1$ and $\mathrm{H} 2$ were selected, and the $\mathrm{MK}$ yields of $\mathrm{H} 1$ and $\mathrm{H} 2$ fermentation products were increased by 42.15 and $40.34 \%$, respectively, compared with that of Monascus albidus 9901 (Wang et al., 2011). Moreover, the mutagenic treatment of ultrasonic wave was also employed to screen Monascus strain producing more MK (Yang et al., 2005b). However, the biological characteristic stability of mutants should be well studied, before commencing the industrial production of FRMR.

Besides the optimization of fermentation parameters, some novel fermentation patterns have also been employed to enhance the MK production (Panda et al., 2010; Zhang et al., 2013; Seenivasan et al., 2020). Metabolic footprinting concept has been used to improve the MK production. A strong glycolytic flux pattern was observed in the shake culture, tricarboxylic acids such as, citric acid, succinic acid, and oxalic acid, apart from glycerol and ethanol are most probably utilized for enhancing production of $\mathrm{MK}$ (Seenivasan et al., 2020). A co-culture of $M$. purpureus and $M$. ruber or $M$. purpureus and Monascus kaoliang showed positive effects on MK production (Panda et al., 2010; Suraiya et al., 2018). On the other hand, agar was tried as a carrier and the MK production of 2,047.03 mg/L was obtained, when the agar concentration, particle size, and glycerol concentration were $4 \%, 4 \times 4 \times 4 \mathrm{~mm}$ and $18 \%$, respectively (Zhang et al., 2013). To meet the individual needs of consumers, novel FRMR needs to be developed.

\section{Novel Nutritious Substrates for FRMR Production}

Novel substrates have been used for Monascus fermentation to enrich the types and functions of FRMR, for instance, soybean flour, finger millet, and Thai glutinous rice (Chairote et al., 2010; Venkateswaran and Vijayalakshmi, 2010; Feng et al., 2014; Table 1). Among the substrates mentioned, substrates rich in starch or protein, for example, soybean flour and Dioscorea are more suitable for Monascus fermentation and MK production (Table 1). Moreover, combining novel 
TABLE 1 | Substrates used for FRMR production.

\begin{tabular}{|c|c|c|c|c|c|c|}
\hline Substrates & Addition & $\begin{array}{l}\text { Fermentation } \\
\text { mode }\end{array}$ & $\begin{array}{l}\text { Fermentation } \\
\text { time (day) }\end{array}$ & Strain & $\begin{array}{l}\text { MK }(\mathrm{mg} / \mathrm{g}) / \\
\text { detection method }\end{array}$ & References \\
\hline Finger millet & Substrate & SSF & 7 & M. purpureus & 0.370/HPLC & $\begin{array}{l}\text { Venkateswaran and } \\
\text { Vijayalakshmi, } 2010\end{array}$ \\
\hline Adlay & Substrate & SSF & 7 & M. purpureus & 1.120/HPLC & Yang et al., 2005a \\
\hline Dioscorea & Substrate & SSF & 10 & M. purpureus NTU 301 & 2.584/HPLC & Lee et al., 2006 \\
\hline Soybean powder & $40 \%$ & SSF & 14 & M. pilosus MS-1 & 18.733/HPLC & Feng et al., 2014 \\
\hline Saccharina japonica & Approximately $48.5 \%$ & SSF & 14.49 & M. purpureus KCCM 60168 & 13.980/HPLC & Suraiya et al., 2018 \\
\hline Mixed grains & Substrate & SSF & 15 & M. pilosus K-1140 & 2.310/HPLC & Pyo and Seo, 2010 \\
\hline Wheat bran & Approximately 25\% & SSF & 16 & M. sanguineus & 20.040/UV & $\begin{array}{l}\text { Dikshit and } \\
\text { Tallapragada, } 2016\end{array}$ \\
\hline Millet & Substrate & SSF & 20 & Monascus ruber & 7.120/HPLC & Zhang et al., 2018b \\
\hline Soybean & Substrate & SSF & 21 & M. sp. K & 0.892/HPLC & Hong et al., 2012 \\
\hline $\begin{array}{l}\text { Thai rice varity Oryza } \\
\text { sativa L. cv. RD6 }\end{array}$ & Substrate & SSF & 21 & M. purpureus CMU001 & 33.790/HPLC & Chairote et al., 2010 \\
\hline
\end{tabular}

SSF, solid-state fermentation.

substrates with rice or with different grains together showed a higher MK production, than using them as sole substrate (Feng et al., 2014; Suraiya et al., 2018). However, it generally needs 2 3 weeks of fermentation to obtain FRMR with MK content of more than $10.00 \mathrm{mg} / \mathrm{g}$. Long-term fermentation of FRMR will increase its risk of contamination (Chairote et al., 2010; Dikshit and Tallapragada, 2016; Suraiya et al., 2018). Therefore, strategies for improving the MK production and further shortening the fermentation period need an urgent attention, especially in consideration to environmentally friendly and natural means. Improving MK production during a fixed conventional fermentation cycle, for example, 14 or 21 days, which equate to shorten the fermentation periods to obtain the required MK contents of FRMR. So, irritants have been used to improve $\mathrm{MK}$ production for the rapid fermentation of FRMR (Zhang et al., 2019; Zhen et al., 2019; Peng et al., 2020).

\section{Improving Monacolin Production Using Irritants}

For efficient production of FRMR, some nutritional and nonnutritional irritants, such as glycerol, glutamic acid, $\mathrm{NaCl}$, and Chinese medicines have been used in medium or substrates, in order to improve the MK production (Lu et al., 2013; Zhang et al., 2019; Zhen et al., 2019; Peng et al., 2020) (Table 2). Generally, higher yield of MK with low cost is expected for commercial purposes. Most of the irritants mentioned above confirm to this expectation. When $10 \mathrm{mM}$ glutamic acid was used in the medium, MK production increased 4.8-fold; the expressions of mokC and mokG and permeability of cell membrane were also increased (Zhang et al., 2017a, 2019). Trace of linoleic acid also achieved the likely results, which was attributed to the fact that linoleic acid increased the cyclic AMP concentration and activated protein kinase that enhanced the MK production (Huang et al., 2018).

MK can be enhanced by glycerol both in LSF and SSF with varying concentrations of glycerol (Lu et al., 2013; Feng et al., 2015). MK yields of fermentation broth and mycelia could be enhanced significantly, when glycerol concentration was adjusted to $6 \mathrm{~g} / \mathrm{L}(p<0.05)$. Concentration of MLs increased and mainly existed in the mycelia after adding glycerol, compared with that of control (Feng et al., 2015). The maximum MK yield of $2.401 \mathrm{mg} / \mathrm{g}$ in mycelia was obtained, when the glycerol concentration was $40 \mathrm{~g} / \mathrm{L}$ (Feng et al., 2015). Furthermore, the maximal MK yield of $12.900 \mathrm{mg} / \mathrm{g}$ was obtained, when 26\% glycerol was used in SSF, with bagasse as a carrier ( $\mathrm{Lu}$ et al., 2013). As an environmentally friendly substance, which could be obtained from byproducts of biodiesel, the comprehensive utilization of glycerol needs to be explored in a future study (Carabajal et al., 2020).

However, most of the irritants are used in LSF instead of SSF at the present research stage. It is inferred that the low addition of the irritants can easily modulate the MK production in LSF, due to rapid mixing and quick fermentation. Irritants used in SSF needs a further study in future research.

\section{STRATEGIES FOR BETTER APPLICATION OF FRMR}

It is well known that MK from FRMR acts as an inhibitor of cholesterol synthesis. Lovastatin and several other statins are marketed as drugs whereas FRMR is offered as a food supplement. Statins can cause side effects such as muscle damage and kidney failure, hence the side effects of FRMR need a critical consideration (Xue et al., 2017). In addition, the quantities of MK in FRMR remain widely variable (Yang and Mousa, 2012). Therefore, it is imperative to evaluate whether FRMR or MLs can be safe and efficient food supplement.

\section{Content Variability and Quality Standardization of FRMR}

Functional red mold rice promotes the maintenance of normal blood low-density lipoprotein (LDL) cholesterol concentrations due to the presence of MLs (De Backer, 2017). FRMR containing 
TABLE 2 | Irritants used for improving MK production.

\begin{tabular}{|c|c|c|c|c|c|c|}
\hline Irritants & Addition & $\begin{array}{l}\text { Fermentation } \\
\text { mode }\end{array}$ & $\begin{array}{l}\text { Fermentation } \\
\text { time (day) }\end{array}$ & Strain & $\begin{array}{l}\text { MK/detection } \\
\text { method }\end{array}$ & References \\
\hline Glycerol & $40 \mathrm{~g} / \mathrm{L}$ & LSF & 7 & M. pilosus MS-1 & $\begin{array}{l}2.401 \mathrm{mg} / \mathrm{g} / \mathrm{HPLC}(\mathrm{MK} \\
\text { yield of mycelia) }\end{array}$ & Feng et al., 2015 \\
\hline $\mathrm{NaCl}$ & $0.02 \mathrm{M}$ & LSF & 10 & $\begin{array}{l}\text { M. purpureus } \\
\text { SKY219 }\end{array}$ & $\begin{array}{l}\text { Approximately } \\
90 \mu \mathrm{g} / \mathrm{mL} / \mathrm{HPLC}(\mathrm{MK} \\
\text { yield of fermentation } \\
\text { broth) }\end{array}$ & Zhen et al., 2019 \\
\hline Dioscorea & $1 \%$ & LSF & 12 & $\begin{array}{l}\text { M. purpureus NTU } \\
568\end{array}$ & $\begin{array}{l}27.9 \mathrm{mg} / \mathrm{g} / \mathrm{HPLC} \text { (MK } \\
\text { yield of mycelia) }\end{array}$ & Lee et al., 2007 \\
\hline Glutamic acid & $10 \mathrm{mM}$ & LSF & 12 & Monascus M1 & $\begin{array}{l}215 \mu \mathrm{g} / \mathrm{mL} / \mathrm{HPLC}(\mathrm{MK} \\
\text { yield of fermentation } \\
\text { broth) }\end{array}$ & Zhang et al., 2017a \\
\hline $\begin{array}{l}\text { Citri Reticulatae } \\
\text { Pericarpium, Poria } \\
\text { cocos, and Radix } \\
\text { Angelicae dahuricae }\end{array}$ & $\begin{array}{l}3.75 \% \text { Citri Reticulatae } \\
\text { Pericarpium, } 2.55 \% \\
\text { Poria cocos, and } \\
2.01 \% \text { Radix }\end{array}$ & SSF & 12 & M. ruber M2-1 & 3.6 mg/g/HPLC & Peng et al., 2020 \\
\hline Sodium nitrate & $1 \%$ & SSF & 14 & $\begin{array}{l}\text { M. purpureus } \\
\text { CCRC } 31615\end{array}$ & 0.378 mg/g/HPLC & Su et al., 2003 \\
\hline Glutamic acid & $10 \mathrm{mM}$ & LSF & 15 & Monascus C8 & $\begin{array}{l}\text { Approximately } \\
450 \mu \mathrm{g} / \mathrm{mL} / \mathrm{HPLC} \text { (MK } \\
\text { yield of fermentation } \\
\text { broth) }\end{array}$ & Zhang et al., 2019 \\
\hline Linoleic acid & $512 \mu \mathrm{M}$ & LSF & 15 & M. ruber cicc 5006 & $\begin{array}{l}\text { Approximately } \\
150 \mu \mathrm{g} / \mathrm{mL} / \mathrm{HPLC}(\mathrm{MK} \\
\text { yield of fermentation } \\
\text { broth) }\end{array}$ & Huang et al., 2018 \\
\hline Glycerol & $26 \%$ & SSF & 20 & M. purpureus 9901 & 12.900 mg/g/HPLC & Lu et al., 2013 \\
\hline Soybean hull & Approximately 50\% & LSF & 30 & $\begin{array}{l}\text { M. pilosus KCCM } \\
60084\end{array}$ & $\begin{array}{l}0.02 \mathrm{mg} / \mathrm{g} / \mathrm{HPLC}(\mathrm{MK} \\
\text { yield of fermentation } \\
\text { product) }\end{array}$ & Simu et al., 2018 \\
\hline
\end{tabular}

LSF, liquid-state fermentation, SSF, solid-state fermentation.

5 7 $\mathrm{mg} \mathrm{MK}$ is considered to be an efficient cholesterollowering agent equivalent to $20 \sim 40 \mathrm{mg}$ of pure lovastatin (Burke, 2015). Standardized FRMR formulation with $10 \mathrm{mg}$ MLs consumed daily has shown to reduce LDL cholesterol by approximately 20\% (McCarty et al., 2015). In 2011, the European Food Safety Authority (EFSA) concluded the existance of a causal relationship between the consumption of lovastatin from FRMR and "maintaining normal LDL cholesterol levels." To obtain the claimed effect, a dose of $\geq 10 \mathrm{mg}$ lovastatin everyday was prescribed (Efsa Panel on Dietetic Products Nutrition, and Allergies. (NDA), 2011). However, the results of percent of $\mathrm{MK}$ in 28 brands of RMR showed a large variability. No presence of MK was detected in two brands of RMR, and $\mathrm{MK}$ range in the other $26 \mathrm{RMR}$ brands ranged more than 60 -fold. The quantity of MK consumed per day would range more than 120-fold, compared with the recommended intake claimed by the manufacturers (Cohen et al., 2017). Some other studies indicate similar results (Heber et al., 2001; Gordon et al., 2010; Song et al., 2012). In addition, the quantity of MK in RMR supplements notified to the health authorities by the manufacturers varies by 30 -fold, which is attributed to the variation in the strain and the fermentation process (De Backer, 2017). The large variation of MK content in RMR supplements could induce large difference in the lipid regulating effects within individuals, which in turn could problems to the efficiency and safety of the RMR supplements. Hence, standardization must be rigorously ensured, as in many cases, the content labeling of RMR supplement is erroneous. The MK content in RMR supplements varies due to the production of RMR with different strains and fermentation process (Patel, 2016; Dujovne, 2017). However, it is worth mentioning that $\mathrm{MK}$ in $0.1 \sim 0.2 \%$ range in RMR is efficient and free of side effects (Halbert et al., 2010). Based on this, effective analytical tools such as chromatography and mass spectrometry can be used to identifiy the discrepancies. In addition, a statement on the product label is required which assures that a toxin-free, nonaugmented, standardized amount of MLs would be advantageous to consumers, which will allow more predictable efficacy and better safety (Nguyen et al., 2017).

FRMR available from markets is with various MK contents, for instance, $0.4,0.8,1.0,1.2,1.5,2.0,2.5$, and 3\%. FRMR with different MK contents varies in price, and the price of FRMR is usually positively correlated with its MK content (Song et al., 2019). For instance, the price of FRMR with MK content of $2 \%$ available from the market is about US\$50 per $1 \mathrm{~kg}$. In addition, FRMR with different product types also varies in price ${ }^{1}$. Therefore, in order to meet drug quality standards, commercial

\footnotetext{
${ }^{1}$ https://www.walgreens.com/store/c/red-yeast-rice/ID=361661-tier3
} 
lovastatin is illegally added to common RMR to imitate FRMR (Song et al., 2019). In view of this, the Hongqu Health Food Standard in 2007 (Taiwan Guardian Food No.0960406448) and the EFSA are currently reassessing the safety of a 10-mg dose of MK as a food supplement (Poli et al., 2018; Song et al., 2019). For the accuracy of MK content, many standards for MLs detection have been established. However, there is no clear requirement for inspection of MK in FRMR according to most of the standards. Some criteria clarify that the required content of $\mathrm{MK}$ lactone in FRMR is generally not less than $0.4 \%$, while just a few of them mention the content requirements of MK lactone and acid forms (Poli et al., 2018; Song et al., 2019). The Standard for Chinese Medicine Yinpian Processing of Sichuan Province (2015) requires that $\mathrm{MK}$ lactone should serve as the quality control of FRMR and the lowest MK content should be $0.4 \%$, which is in accordance with the standard of the "Functional red yeast rice QB/T 2847-2007.” The Standard for Chinese Medicine Yinpian Processing of Zhejiang Provine (2015) indicated that the total of MK lactone and acid in FRMR should be more than $0.3 \%$, and the peak area of acid MK must not be less than $5 \%$ of the lactone MK peak area.

In order to distinguish commercial lovastatin from $\mathrm{MK}$, some efficient detection methods such as UHPLC-QQQ-MS, UHPLC-Q-TOF-MAS, and stable isotope ration analysis $\left({ }^{13} \mathrm{C}\right.$ NMR) have been employed to authenticate the FRMR (Zhu et al., 2013; Perini et al., 2017). Moreover, it is demonstrated that the analysis of $\delta^{13} \mathrm{C}$ with isotope ratio mass spectrometry could authenticate the FRMR (Song et al., 2019). All the aforementioned strategies relate to standardize the MK content in RMR and authenticate the FRMR, thereby laying the foundation for standardization of FRMR.

\section{Safety Evaluation of FRMR}

Functional red mold rice has always been used as an alternative lipid-lowering therapy for patients who are unable to tolerate the statin therapy, due to statin-associated myalgias (Gordon and Becker, 2011). However, the variability of MK content, potential of toxic byproducts, and no clinical data on the FRMR dietary supplement indicate that the patients should be cautious before FRMR is standardized (Venhuis et al., 2016). As of date, some side effects of FRMR have been reported, such as myopathy, erectile dysfunction, and liver injury, etc. (Polsani et al., 2008; Childress et al., 2013; Mazzanti et al., 2017; Liu and Chen, 2018). On the other hand, among dyslipidemic patients with low to moderate cardiovascular risk, FRMR induces less muscle fatigue symptoms and exerts comparable lipid-lowering effects, when compared with simvastatin in single-center randomized pilot trials (Xue et al., 2017). Therefore, safety evaluation of FRMR is an urgent and important subject.

It has been confirmed that the safety profile of FRMR is similar to that of statins (Mazzanti et al., 2017). Therefore, the composition and formulation of FRMR dietary supplement is particularly important due to the presence of MLs; besides, MK may also act as HMG-CoA-reductase inhibitors (Li et al., 2004). For instance, compactin is likely to be only half as effective, with respect to $\mathrm{HMG}-\mathrm{CoA}$ reductase inhibition as
MK (Heber et al., 2001; Li et al., 2004). Therefore, the bioavailability of the individual MLs is difficult to determine, in the presence of MK. It may be useful to specify a total MLs content in the form of monacolin equivalents. This hypothesis suggests that FRMR can be considered an unregistered medicine (Farkouh and Baumgärtel, 2019).

In addition, citrinin is a confirmed nephrotoxic and teratogenic agent present in FRMR, which is another obstacle for using FRMR as food supplement or medicine. Therefore, Monascus strains with high MK production and low even undetectable citrinin have been screened (Li et al., 2020). Additives such as soybean isoflavones and $\mathrm{NaCl}$ were also used to reduce citrinin production (Huang et al., 2019; Zhen et al., 2019; He et al., 2020a). Meanwhile, detection of citrinin in FRMR is also a matter of great concern and HPLC is usually used to detect citrinin in FRMR ( $\mathrm{Li}$ et al., 2020). For the efficient detection of citrinin in FRMR, immunoaffinity column is employed for citrinin extraction according to the Chinese National Standards for Determination of Citrinin in Food (GB 5009.222-2016). Moreover, additive pharmacological effects may be expected for other MLs present (Venhuis et al., 2016). It should be suggested that the consumers taking FRMR should do a blood test for cholesterol before taking the FRMR dietary supplement. It should also be noted that taking FRMR and statins at the same time can easily lead to overdosing and side effects. Without active postmarket surveillance for adverse drug reactions, the valuable signals of product safety are lost. If the current regulatory status for pharmacologically effective FRMR dietary supplements do not permit adequate warnings and active monitoring of adverse drug reactions, then their regulatory status may not be appropriate (Venhuis et al., 2016).

Based on this, some strategies like the continuous monitoring of "natural" dietary supplement safety through spontaneous reports, long-term trials, appropriate information to clinicians and consumers, and timely submission of suspect reports to regulatory agencies, should be carried out (Mazzanti et al., 2017). Moreover, three important points need to be taken into consideration: (1) Recognizing that FRMR contains a statin-like compound; (2) carefully recommending FRMR to statin-intolerant patients with a history of myositis or myopathy; (3) Documenting all alternative medicines, such as FRMR, taken by patients, in order to weigh the benefit-to-risk of co-administration of other drugs (Polsani et al., 2008). Overall, the real-world vigilance should be strengthened at different levels, including consumers, clinicians and policy-makers to promote the proper use and harmonize the regulatory status of FRMR (Raschi et al., 2018; Farkouh and Baumgärtel, 2019).

\section{CONCLUSION}

Functional red mold rice has been used as a folk medicine by people suffering from hyperlipidemia. However, besides MK, other MLs, pigments, and citrinin in FRMR show multiple activities, sometimes even resulting in toxicity to the consumers. 
For improving the MK content and optimizing the product type of FRMR, fermentation parameters should be optimized and the used of novel substrates or irritants should be employed for FRMR production. Standardization of MK contents in FRMR and evaluation of FRMR safety should be studied in detail. Based on this, a better application of FRMR as a safe and effective lipid-lowering agent can be actualized.

\section{DATA AVAILABILITY STATEMENT}

The original contributions presented in the study are included in the article/supplementary material, further inquiries can be directed to the corresponding author.

\section{REFERENCES}

Avula, B., Cohen, P. A., Wang, Y. H., Sagi, S., Feng, W., Wang, M., et al. (2014). Chemical profiling and quantification of monacolins and citrinin in red yeast rice commercial raw materials and dietary supplements using liquid chromatography-accurate QToF mass spectrometry: chemometrics application. J. Pharmaceut. Biomed. 100, 243-253. doi: 10.1016/j.jpba.2014.07. 039

Beltrán, D., Frutos-Lisón, M. D., Espín, J. C., and García-Villalba, R. (2019). Reexamining the role of the gut microbiota in the conversion of the lipid-lowering statin monacolin $\mathrm{K}$ (lovastatin) into its active $\beta$-hydroxy acid metabolite. Food Funct. 10, 1787-1791. doi: 10.1039/C8FO02594K

Bruno, A., Pandolfo, G., Crucitti, M., Troili, G. M., Spina, E., Zoccali, R. A., et al. (2018). Red Yeast Rice (RYR) supplementation in patients treated with second-generation antipsychotics. Complement. Ther. Med. 37, 167-171. doi: 10.1016/j.ctim.2018.03.007

Burke, F. (2015). Red yeast rice for the treatment of dyslipidemia. Curr. Atheroscler. Rep. 17:495.

Carabajal, M. D., Glorio, A., Marcipar, I. S., and Lagier, C. M. (2020). Determination of free and total glycerol in biodiesel by spot analysis. Microchem. J 158:105148. doi: 10.1016/j.microc.2020.105148

Chairote, E. O., Lumyong, S., and Chairote, G. (2010). Study on cholesterol lowering compounds in red yeast rice prepared form thai glutinous rice. Asian J. Food Agro Ind. 3, 217-228.

Chen, W., Feng, Y., Molnár, I., and Chen, F. (2019). Nature and nurture: confluence of pathway determinism with metabolic and chemical serendipity diversifies Monascus azaphilone pigments. Nat. Prod. Rep. 36, 561-572. doi: 10.1039/ C8NP00060C

Chen, Y., Tseng, C., Liaw, L., Wang, C., Chen, I., Wu, W., et al. (2008). Cloning and characterization of monacolin K biosynthetic gene cluster from Monascus pilosus. J. Agric. Food Chem. 56, 5639-5646. doi: 10.1021/jf800595k

Childress, L., Gay, A., Zargar, A., and Ito, M. K. (2013). Review of red yeast rice content and current Food and Drug Administration oversight. J. Clin. Lipidol. 7, 117-122. doi: 10.1016/j.jacl.2012.09.003

Cicero, A. F. G., Fogacci, F., Rosticci, M., Parini, A., Giovannini, M., Veronesi, M., et al. (2017). Effect of a short-term dietary supplementation with phytosterols, red yeast rice or both on lipid pattern in moderately hypercholesterolemic subjects: a three-arm, double-blind, randomized clinical trial. Nutr. Metab. 14, 61-67. doi: 10.1186/s12986-017-0214-2

Cohen, P. A., Avula, B., and Khan, I. A. (2017). Variability in strength of red yeast rice supplements purchased from mainstream retailers. Eur. J. Prev. Cardiol. 24, 1431-1434. doi: 10.1177/2047487317715714

D'Addato, S., Scandiani, L., Mombelli, G., Focanti, F., Pelacchi, F., Salvatori, E., et al. (2017). Effect of a food supplement containing berberine, monacolin $\mathrm{K}$, hydroxytyrosol and coenzyme Q10 on lipid levels: a randomized, doubleblind, placebo controlled study. Drug Des. Dev. Ther. 2017, 1585-1592. doi: 10.2147/DDDT.S128623

De Backer, G. G. (2017). Food supplements with red yeast rice: more regulations are needed. Eur. J. Prev. Cardiol. 24, 1429-1430. doi: 10.1177/2047487317716500

\section{AUTHOR CONTRIBUTIONS}

FY drafted the main parts of the manuscript. YX contributed to parts of the manuscript. Both authors approved the manuscript.

\section{FUNDING}

This work was supported by Key Project of Research Project of the Education Department of Hubei Province in China (No. D20192502), Open Fund of Hubei Key Laboratory of Edible Wild Plants Conservation and Utilization (No. EWPL201807), and Research Innovation Team Project of Hubei Normal University (2019CZ07).

del Gaudio, F., Guerrera, I. C., Riccio, R., and Monti, M. C. (2020). Quantitative proteomics discloses monacolin $\mathrm{K}$-induced alterations in triple-negative breast cancer cell proteomes and phosphoproteomes. Mol. Omics 16, 19-30. doi: 10. 1039/C9MO00140A

Dhale, M., Divakar, S., Kumar, S. U., and Vijayalakshmi, G. (2007a). Isolation and characterization of dihydromonacolin-MV from Monascus purpureus for antioxidant properties. Appl. Microbiol. Biotechnol. 73, 1197-1202. doi: 10.1007/ s00253-006-0578-0

Dhale, M. A., Divakar, S., Umesh-Kumar, S., and Vijayalakshmi, G. (2007b). Characterization of dehydromonacolin-MV2 from Monascus purpureus mutant. J. Appl. Microbiol. 103, 2168-2173. doi: 10.1111/j.1365-2672.2007. 03457.x

Di Pierro, F., Putignano, P., Ferrara, T., Raiola, C., Rapacioli, G., and Villanova, N. (2016). Retrospective analysis of the effects of a highly standardized mixture of Berberis aristata, Silybum marianum, and monacolins $\mathrm{K}$ and KA in patients with dyslipidemia. Clin. Pharm. Adv. Appl. 2017, 1-7. doi: 10.2147/CPAA. S120032

Dikshit, R., and Tallapragada, P. (2016). Statistical optimization of lovastatin and confirmation of nonexistence of citrinin under solid-state fermentation by Monascus sanguineus. J. Food Drug Anal. 24, 433-440. doi: 10.1016/j.jfda.2015. 11.008

Dujovne, C. A. (2017). Red yeast rice preparations: are they suitable substitutions for statins? Am. J. Med. 130, 1148-1150. doi: 10.1016/j.amjmed.2017. 05.013

Efsa Panel on Dietetic Products Nutrition, and Allergies. (NDA) (2011). Scientific opinion on the substantiation of health claims related to monacolin $\mathrm{K}$ from red yeast rice and maintenance of normal blood LDL-cholesterol concentrations (ID 1648, 1700) pursuant to Article 13(1) of Regulation (EC) No 1924/2006. EFSA J 9:2304.

Endo, A. (1979). Monacolin K, a new hypocholesterolemic agent produced by a Monascus species. J. Antibiot. 32, 852-854. doi: 10.7164/antibiotics.32.852

Endo, A. (1985b). Monacolins J and L, new inhibitors of cholesterol biosynthesis produced by Monascus ruber. J. Antibiot. 38, 420-422. doi: 10.7164/antibiotics. 38.420

Endo, A. (1985a). Compactin (ML-236B) and related compounds as potential cholesterol-lowering agents that inhibit HMG-CoA reductase. J. Med. Chem. 28, 401-405. doi: 10.1021/jm00382a001

Endo, A., and Hasumi, K. (1985). Dihydromonacolin L and monacolin X, new metabolites those Inhibit cholesterol biosynthesis. J. Antibiot 38, 321-327. doi: 10.7164/antibiotics.38.321

Endo, A., Komagata, D., and Shimada, H. (1986). Monacolin M, a new inhibitor of cholesterol biosynthesis. J. Antibiot. 39, 1670-1673. doi: 10.7164/antibiotics.39. 1670

Ertürk, S., Önal, A., and Müge Çetin, S. (2003). Analytical methods for the quantitative determination of 3-hydroxy-3-methylglutaryl coenzyme A reductase inhibitors in biological samples. J. Chromatogr. B 793, 193-205. doi: 10.1016/S1570-0232(03)00314-3

Fang, Y. X., Song, H. P., Liang, J. X., Li, P., and Yang, H. (2017). Rapid screening of pancreatic lipase inhibitors from Monascus-fermented rice by ultrafiltration 
liquid chromatography-mass spectrometry. Anal. Methods 238:111879. doi: 10. 1039/C7AY00777A

Farkouh, A., and Baumgärtel, C. (2019). Mini-review: medication safety of red yeast rice products. Int. J. Gen. Med. 2019, 167-171. doi: 10.2147/ijgm.s202446

Feng, Y. L., Shao, Y. C., Zhou, Y. X., and Chen, F. S. (2014). Production and optimization of monacolin K by citrinin-free Monascus pilosus MS-1 in solidstate fermentation using non-glutinous rice and soybean flours as substrate. Eur. Food Res. Technol. 239, 629-636. doi: 10.1007/s00217-014-2259-z

Feng, Y. L., Shao, Y. C., Zhou, Y. X., and Chen, F. S. (2015). Effects of glycerol on pigments and monacolin $\mathrm{K}$ production by the high-monacolin K-producing but citrinin-free strain, Monascus pilosus MS-1. Eur. Food Res. Technol. 240, 635-643. doi: 10.1007/s00217-014-2365-y

Formisano, E., Pasta, A., Cremonini, A. L., Favari, E., Ronca, A., Carbone, F., et al. (2019). Efficacy of nutraceutical combination of monacolin K, berberine, and silymarin on lipid profile and PCSK9 plasma level in a cohort of hypercholesterolemic patients. J. Med. Food 23, 658-666. doi: 10.1089/jmf.2019. 0168

Gordon, R., and Becker, D. (2011). The role of red yeast rice for the physician. Curr. Atheroscler. Rep. 13, 73-80. doi: 10.1007/s11883-010-0145-0

Gordon, R. Y., Cooperman, T., Obermeyer, W., and Becker, D. J. (2010). Marked variability of monacolin levels in commercial red yeast rice products: buyer beware! Arch. Intern. Med. 170, 1722-1727. doi: 10.1001/archinternmed.2010. 382

Hachem, R., Assemat, G., Balayssac, S., Martins-Froment, N., Gilard, V., Martino, R., et al. (2020). Comparative chemical profiling and monacolins quantification in red yeast rice dietary supplements by $1 \mathrm{H}-\mathrm{NMR}$ and UHPLC-DAD-MS. Molecules 25, 317-349. doi: 10.3390/molecules25020317

Halbert, S., French, B., and Gordon, R. (2010). Tolerability of red yeast rice $(2,400$ $\mathrm{mg}$ twice daily) versus pravastatin (20 $\mathrm{mg}$ twice daily) in patients with previous statin intolerance. Am. J. Cardiol. 105, 198-204. doi: 10.1016/j.amjcard.2009.08. 672

He, S., Liu, X., Wang, Y., Xie, J., Gao, H., Li, X., et al. (2020a). Metabolomics analysis based on UHPLC-Q-TOF-MS/MS reveals effects of genistein on reducing mycotoxin citrinin production by Monascus aurantiacus Li AS3.4384. LWT 130:109613. doi: 10.1016/j.lwt.2020.109613

He, S., Wang, Y., Xie, J., Gao, H., Li, X., and Huang, Z. (2020b). 1H NMRbased metabolomic study of the effects of flavonoids on citrinin production by Monascus. Food Res. Int. 137:109532. doi: 10.1016/j.foodres.2020.10 9532

Heber, D., Lembertas, A., Lu, Q., Bowerman, S., and Go, V. (2001). An analysis of nine proprietary Chinese red yeast rice dietary supplements: implications of variability in chemical profile and contents. J. Altern. Complement. Med. 7, 133-139. doi: 10.1089/107555301750164181

Heinz, T., Schuchardt, J. P., Möller, K., Hadji, P., and Hahn, A. (2016). LDLcholesterol-lowering effect of monacolin $\mathrm{K}$ from red yeast rice extract - results of a randomized, placebo-controlled intervention study. Nutr. Res. 36, 11621170. doi: 10.1016/j.nutres.2016.07.005

Hong, S., Lee, I., Kim, S., and Imm, J. Y. (2012). Improved functionality of soft soybean curd containing Monascus fermented soybean ethanol extract. Food Sci. Biotechnol. 21, 701-707. doi: 10.1007/s10068-012-0091-4

Hp, M. K. (2012). Optimization of monacolin K production by Monascus purpureus MTTC 410 in submerged fermentation. Int. J. Food Eng. 8, 1-12. doi: $10.1515 / 1556-3758.1420$

Huang, J., Liao, N., and Li, H. (2018). Linoleic acid enhance the production of moncolin $\mathrm{K}$ and red pigments in Monascus ruber by activating mokH and mokA, and by accelerating cAMP-PkA pathway. Int. J. Biol. Macromol 109, 950-954. doi: 10.1016/j.ijbiomac.2017.11.074

Huang, Z., Zhang, L., Gao, H., Wang, Y., Li, X., Huang, X., et al. (2019). Soybean isoflavones reduce citrinin production by Monascus aurantiacus Li AS3.4384 in liquid state fermentation using different media. J. Sci. Food Agri. 99, 4772-4780. doi: $10.1002 /$ jsfa. 9723

Iskandar, I., Harahap, Y., Wijayanti, T. R., Sandra, M., Prasaja, B., and Cahyaningsih, P. (2020). Efficacy and tolerability of a nutraceutical combination of red yeast rice, guggulipid, and chromium picolinate evaluated in a randomized, placebo-controlled, double-blind study. Complement. Ther. Med 48:102282. doi: 10.1016/j.ctim.2019.102282

Jiang, Y., Lv, X., Zhang, C., Zheng, Y., Zheng, B., Duan, X., et al. (2019). Microbial dynamics and flavor formation during the traditional brewing of
Monascus vinegar. Food Res. Int. 125:108531. doi: 10.1016/j.foodres.2019. 108531

Kimura, K., Komagata, D., Murakawa, S., and Endo, A. (1990). Biosynthesis of monacolins: conversion of monacolin J to monacolin K (mevinolin). J. Antibiot. 43, 1621-1622. doi: 10.7164/antibiotics.43.1621

Kurokawa, H., Ito, H., and Matsui, H. (2017). Monascus purpureus induced apoptosis on gastric cancer cell by scavenging mitochondrial reactive oxygen species. J. Clin. Biochem. Nutr. 61, 189-195. doi: 10.3164/jcbn.17-27

Lee, C. L., Hung, H. K., Wang, J. J., and Pan, T. M. (2007). Improving the ratio of monacolin K to citrinin production of Monascus purpureus NTU 568 under dioscorea medium through the mediation of $\mathrm{pH}$ value and ethanol addition. J. Agr. Food Chem. 55, 6493-6502. doi: 10.1021/jf0711946

Lee, C. L., Wang, J. J., Kuo, S. L., and Pan, T. M. (2006). Monascus fermentation of dioscorea for increasing the production of cholesterol-lowering agent-monacolin K and antiinflammation agent-monascin. Appl. Microbiol. Biotechnol. 72, 1254-1262. doi: 10.1007/s00253-006-0404-8

Lee, Y. L., Yang, J. H., and Mau, J. L. (2009). Antioxidant properties of ethanolic and methanolic extracts from Monascus-fermented soybeans. J. Food Biochem. 33, 707-727. doi: 10.1111/j.1745-4514.2009.00246.x

Li, M. N., Li, C. R., Gao, W., Li, P., and Yang, H. (2017). Highly sensitive strategy for identification of trace chemicals in complex matrix: Application to analysis of monacolin analogues in monascus-fermented rice product. Anal. Chim. Acta 982, 156-167. doi: 10.1016/j.aca.2017.05.030

Li, Y., Zhang, F., Wang, Z., and Hu, Z. (2004). Identification and chemical profiling of monacolins in red yeast rice using high-performance liquid chromatography with photodiode array detector and mass spectrometry. J. Pharm. Biomed. Anal. 35, 1101-1112. doi: 10.1016/j.jpba.2004.04.004

Li, Z., Liu, Y., Li, Y., Lin, F., and Wu, L. (2020). Screening and identification of Monascus strains with high-yield monacolin $\mathrm{K}$ and undetectable citrinin by integration of HPLC analysis and pksCT and ctnA genes amplification. J. Appl. Microbiol. 129, 1410-1418. doi: 10.1111/jam.14689

Liang, J. X., Zhang, Q. Q., Huang, Y. F., Pang, H. Q., Liu, X. G., Gao, W., et al. (2019). Comprehensive chemical profiling of monascus-fermented rice product and screening of lipid-lowering compounds other than monacolins. J. Ethnopharmacol. 238:111879. doi: 10.1016/j.jep.2019.111879

Lin, L., Wang, C., Li, Z., Wu, H., and Chen, M. (2017). Effect of temperatureshift and temperature-constant cultivation on the monacolin $\mathrm{K}$ biosynthetic gene cluster expression in Monascus sp. Food Technol. Biotechnol. 55, 40-47. doi: $10.17113 / \mathrm{ftb} .55 .01 .17 .4729$

Liu, M. T., Li, J. J., Shang, X. Y., Li, S., Li, L. L., Luan, N., et al. (2011). Structure elucidation and complete NMR spectral assignment of an unusual aromatic monacolin analog from Monascus purpureus-fermented rice. Magn. Reson. Chem. 49, 129-131. doi: 10.1002/mrc.2714

Liu, M. T., Wang, A. L., Sun, Z., Li, J. J., Wu, X. L., Liu, Y. X., et al. (2013). Cytotoxic monacolin analogs from Monascus purpureus-fermented rice. J. Asian Nat. Prod. Res. 15, 600-609. doi: 10.1080/10286020.2013.790379

Liu, Z., and Chen, P. (2018). A case of erectile dysfunction induced by red yeast rice in lipidlowering therapy. Phytother. Res. 32, 953-954. doi: 10.1002/ptr.6025

Lu, L. P., Zhang, B. B., and Xu, G. R. (2013). Efficient conversion of high concentration of glycerol to monacolin $\mathrm{K}$ by solid-state fermentation of Monascus purpureus using bagasse as carrier. Bioproce. Biosyst. Eng. 36, 293299. doi: 10.1007/s00449-012-0784-3

Mazza, A., Lenti, S., Schiavon, L., Di Giacomo, E., Tomasi, M., Manunta, R., et al. (2018). Effect of Monacolin $\mathrm{K}$ and $\mathrm{CO}_{\mathrm{Q} 10}$ supplementation in hypertensive and hypercholesterolemic subjects with metabolic syndrome. Biomed. Pharmacother. 105, 992-996. doi: 10.1016/j.biopha.2018.06.076

Mazzanti, G., Moro, P. A., Raschi, E., Da Cas, R., and Menniti-Ippolito, F. (2017). Adverse reactions to dietary supplements containing red yeast rice: assessment of cases from the Italian surveillance system. Brit. J. Clin. Pharmacol. 83, 894-908. doi: 10.1111/bcp.13171

McCarty, M., O'Keefe, J., and DiNicolantonio, J. (2015). Red yeast rice plus berberine: practical strategy for promoting vascular and metabolic health. Altern. Ther. Health Med. 21, 40-45.

Mohan-Kumari, H. P., Dhale, M. A., Akhilender Naidu, K., and Vijayalakshmi, G. (2011). Antioxidant effect of red mould rice in hypercholesterolemic Wistar male rats. Cell Biochem. Funct. 29, 597-602. doi: 10.1002/cbf.1793

Nagabhishek, S. N., and Madankumar, A. (2019). A novel apoptosis-inducing metabolite isolated from marine sponge symbiont Monascus sp. NMK7 
attenuates cell proliferation, migration and ROS stress-mediated apoptosis in breast cancer cells. RSC Adv. 9, 5878-5890. doi: 10.1039/C8RA09886G

Nguyen, T., Karl, M., and Santini, A. (2017). Red yeast rice. Foods 6:19. doi: 10.3390/foods6030019

Panda, B., Javed, S., and Ali, M. (2010). Optimization of fermentation parameters for higher lovastatin production in red mold rice through co-culture of Monascus purpureus and Monascus ruber. Food Bioprocess Tech. 3, 373-378. doi: 10.1007/s11947-008-0072-z

Patel, S. (2016). Functional food red yeast rice (RYR) for metabolic syndrome amelioration: a review on pros and cons. World J. Microb. Biot. 32:87. doi: 10.1007/s11274-016-2035-2

Peng, L., Ai-lati, A., Liu, S., Ji, Z., Mao, J., and Che, X. (2020). Effects of Chinese medicines on monacolin $\mathrm{K}$ production and related genes transcription of Monascus ruber in red mold rice fermentation. Food Sci. Nutr. 8, 2134-2142. doi: $10.1002 /$ fsn 3.1511

Perini, M., Carbone, G., and Camin, F. (2017). Stable isotope ratio analysis for authentication of red yeast rice. Talanta 174, 228-233. doi: 10.1016/j.talanta. 2017.05.057

Poli, A., Barbagallo, C. M., Cicero, A. F. G., Corsini, A., Manzato, E., Trimarco, B., et al. (2018). Nutraceuticals and functional foods for the control of plasma cholesterol levels. An intersociety position paper. Pharmacol. Res. 134, 51-60. doi: 10.1016/j.phrs.2018.05.015

Polsani, V. R., Jones, P. H., Ballantyne, C. M., and Nambi, V. (2008). A case report of myopathy from consumption of red yeast rice. J. Clin. Lipidol. 2, 60-62. doi: $10.1016 /$ j.jacl.2007.12.005

Praveen, V., and Savitha, J. (2012). Solid state fermentation: an effective method for lovastatin production by fungi over submerged fermentation. J. Biotechnol. Pharm. Res. 3, 15-21.

Pyo, Y. H., and Seo, S. Y. (2010). Simultaneous production of natural statins and coenzyme Q10 by Monascus pilosus fermentation using different solid substrates. Food Sci. Biotechnol. 19, 1635-1641. doi: 10.1007/s10068-010-02317

Raschi, E., Girardi, A., Poluzzi, E., Forcesi, E., Menniti-Ippolito, F., Mazzanti, G., et al. (2018). Adverse events to food supplements containing red yeast rice: cmparative analysis of FAERS and CAERS reporting systems. Drug Safety 41, 745-752. doi: 10.1007/s40264-018-0661-3

Seenivasan, A., Satya Eswari, J., Sankar, P., Gummadid, S. N., Pandae, T., and Venkateswarluf, C. (2020). Metabolic pathway analysis and dynamic macroscopic model development for lovastatin production by Monascus purpureus using metabolic footprinting concept. Biochem. Eng. J. 154:107437. doi: 10.1016/j.bej.2019.107437

Simu, S. Y., Castro-Aceituno, V., Lee, S., Ahn, S., Lee, H. K., Hoang, V. A., et al. (2018). Fermentation of soybean hull by Monascus pilosus and elucidation of its related molecular mechanism involved in the inhibition of lipid accumulation. An in sílico and in vitro approach. J. Food Biochem. 42:e12442. doi: 10.1111/ jfbc. 12442

Song, F., El-Demerdash, A., Lee, S. S., and Smith, R. (2012). Fast screening of lovastatin in red yeast rice products by flow injection tandem mass spectrometry. Pharm. Biomed. Anal. Chem. 57, 76-81. doi: 10.1016/j.jpba.2011. 08.039

Song, J., Luo, J., Ma, Z., Sun, Q., Wu, C., and Li, X. (2019). Quality and authenticity control of functional red yeast rice-a review. Molecules 24:1944. doi: 10.3390/ molecules24101944

Stefanutti, C., Mazza, F., Mesce, D., Morozzi, C., Di Giacomo, S., Vitale, M., et al. (2017). Monascus purpureus for statin and ezetimibe intolerant heterozygous familial hypercholesterolaemia patients: a clinical study. Atherosclerosis Supp. 30, 86-91. doi: 10.1016/j.atherosclerosissup.2017.05.021

Su, Y. C., Wang, J. J., Lin, T. T., and Pan, T. M. (2003). Production of the secondary metabolites $\gamma$-aminobutyric acid and monacolin $\mathrm{K}$ by Monascus. J. Ind. Microbiol. Biot. 30, 41-46. doi: 10.1007/s10295-002-0001-5

Subhagar, S., Aravindan, R., and Viruthagiri, T. (2009). Response surface optimization of mixed substrate solid state fermentation for the production of lovastatin by Monascus purpureus. Eng. Life Sci. 9, 303-310. doi: 10.1002/elsc. 200900022

Suh, S. H., Rheem, S., Mah, J.-H., Lee, W., Byun, M.-W., and Hwang, H.-J. (2007). Optimization of production of monacolin $\mathrm{K}$ from $\gamma$-irradiated Monascus mutant by ue of response surface methodology. J. Med. Food 10, 408-415. doi: 10.1089/jmf.2006.097
Suraiya, S., Kim, J. H., Tak, J. Y., Siddique, M. P., Young, C. J., Kim, J. K., et al. (2018). Influences of fermentation parameters on lovastatin production by Monascus purpureus using Saccharina japonica as solid fermented substrate. LWT 92, 1-9. doi: 10.1016/j.lwt.2018.02.013

Tien, A. J., Chueh, T. H., Hsia, C. P., and Chien, C. T. (2016). Monascus adlay and monacolin $\mathrm{K}$ attenuates arterial thrombosis in rats through the inhibition of ICAM-1 and oxidative stress. Kidney Blood Press. Res. 41, 815-827. doi: $10.1159 / 000452584$

Tseng, Y. H., Yang, J. H., Chen, C. H., and Mau, J. L. (2011). Quality and antioxidant properties of Anka-enriched bread. J. Food Process. Pres. 35, 518-523. doi: 10.1111/j.1745-4549.2010.00497.x

Tsukahara, M., Shinzato, N., Tamaki, Y., Namihira, T., and Matsui, T. (2009). Red yeast rice fermentation by selected Monascus sp. with deep-red color, lovastatin production but no citrinin, and effect of temperature-shift cultivation on lovastatin production. Appl. Biochem. Biotechnol. 158, 476-482. doi: 10.1007/ s12010-009-8553-8

Venhuis, B. J., van Hunsel, F., van de Koppel, B. S., Keizers, B. P. H. J., Jeurissena, S. M. F., and De Kaste, D. (2016). Pharmacologically effective red yeast rice preparations marketed as dietary supplements illustrated by a case report. Drug Test. Anal. 8, 315-318. doi: 10.1002/dta.1929

Venkateswaran, V., and Vijayalakshmi, G. (2010). Finger millet (Eleusine coracana) - an economically viable source for antihypercholesterolemic metabolites production by Monascus purpureus. J. Food Sci. Technol. 47, 426-431. doi: 10.1007/s13197-010-0070-9

Wang, L., Wang, W., and Xu, G. (2011). Promotion of monacolin K production by Agrobacterium tumefaciens-mediated transformation in Monascus albidus 9901. Curr. Microbiol. 62, 501-507. doi: 10.1007/s00284-010-9735-x

Wang, P., Chen, D., Jiang, D., Dong, X., Chen, P., and Lin, Y. (2014). Alkali extraction and in vitro antioxidant activity of Monascus mycelium polysaccharides. J. Food Sci. Technol. 51, 1251-1259. doi: 10.1007/s13197-0120618-y

Wang, T. J., Lien, A. S. Y., Chen, J. L., Lin, C. H., Yang, Y. S., and Yang, S. H. (2019). A randomized clinical efficacy trial of red yeast rice (Monascus pilosus) against hyperlipidemia. Am. J. Chinese Med. 47, 323-335. doi: 10.1142/ S0192415X19500150

Wong, R., and Rabie, B. (2008). Chinese red yeast rice (Monascus purpureusfermented rice) promotes bone formation. Chin. Med. U.K. 3, 1-6. doi: 10.1186/ 1749-8546-3-4

Xiong, Z., Cao, X., Wen, Q., Chen, Z., Cheng, Z., Huang, X., et al. (2019). An overview of the bioactivity of monacolin K / lovastatin. Food Chem. Toxicol. 131:110585. doi: 10.1016/j.fct.2019.11 0585

Xu, B., Wang, Q., and Sung, C. (2017). Telomerase inhibitory effects of red pigment rubropunctatin and statin monacolin L isolated from red yeast rice. Genes 8, 129-138. doi: 10.3390/genes8050129

Xu, B. J., Wang, Q. J., Jia, X. Q., and Sung, C. K. (2005). Enhanced lovastatin production by solid state fermentation of Monascus ruber. Biotechnol. Bioproc. E. 10, 78-84. doi: 10.1007/bf029 31187

Xue, Y., Tao, L., Wu, S., Wang, G., Qian, L., Li, J., et al. (2017). Red yeast rice induces less muscle fatigue symptom than simvastatin in dyslipidemic patients: a single center randomized pilot trial. BMC Cardiovasc. Disord. 17:127. doi: 10.1186/s12872-017-0560-z

Yang, C. W., and Mousa, S. A. (2012). The effect of red yeast rice (Monascus purpureus) in dyslipidemia and other disorders. Complement. Ther. Med. 20, 466-474. doi: 10.1016/j.ctim.2012.07.004

Yang, D. J., and Hwang, L. S. (2006). Study on the conversion of three natural statins from lactone forms to their corresponding hydroxy acid forms and their determination in Pu-Erh tea. J. Chromatogr. A 1119, 277-284. doi: 10.1016/j. chroma.2005.12.031

Yang, J. H., Tseng, Y. H., Chang, H. L., Lee, Y. L., and Mau, J. L. (2005a). Storage stability of monascal adlay. Food Chem. 90, 303-309. doi: 10.1016/j.foodchem. 2004.03.053

Yang, S., Zhang, H., Li, Y., Qian, J., and Wang, W. (2005b). The ultrasonic effect on biological characteristics of Monascus sp. Enzyme Microb. Tech. 37, 139-144. doi: 10.1016/j.enzmictec.2005.02.005

Zhang, B., Liu, T. X., Wang, A. L., Li, J. J., Wang, X., Luan, N., et al. (2018a). Four new monacolin analogs from Monascus purpureus-fermented 
rice. J. Asian Nat. Prod. Res. 20, 209-216. doi: 10.1080/10286020.2017.139 6978

Zhang, B. B., Lu, L. P., Xia, Y. J., Wang, Y. L., and Xu, G. R. (2013). Use of agar as carrier in solid-state fermentation for Monacolin K production by Monascus: A novel method for direct determination of biomass and accurate comparison with submerged fermentation. Biochem. Eng. J. 80, 10-13. doi: 10.1016/j.bej. 2013.09.007

Zhang, B. B., Xing, H. B., Jiang, B. J., Chen, L., Xu, G. R., Jiang, Y., et al. (2018b). Using millet as substrate for efficient production of monacolin $\mathrm{K}$ by solid-state fermentation of Monascus ruber. J. Biosci. Bioeng. 125, 333-338. doi: 10.1016/j. jbiosc.2017.10.011

Zhang, C., Chai, S., Hao, S., Zhang, A., Zhu, Q., Zhang, H., et al. (2019). Effects of glutamic acid on the production of monacolin $\mathrm{K}$ in four high-yield monacolin $\mathrm{K}$ strains in Monascus. Appl. Microbiol. Biotechnol. 103, 5301-5310. doi: 10.1007/ s00253-019-09752-9

Zhang, C., Liang, J., Yang, L., Chai, S., Zhang, C., Sun, B., et al. (2017a). Glutamic acid promotes monacolin $\mathrm{K}$ production and monacolin $\mathrm{K}$ biosynthetic gene cluster expression in Monascus. AMB Expr. 7:22. doi: 10.1186/s13568-0160311-z

Zhang, C., Liang, J., Yang, L., Sun, B., and Wang, C. (2017b). De novo RNA sequencing and transcriptome analysis of Monascus purpureus and analysis of key genes involved in monacolin K biosynthesis. PLoS One 12:e170149. doi: 10.1371/journal.pone.0170149

Zhang, Y., Chen, Z., Wen, Q., Xiong, Z., Cao, X., Zheng, Z., et al. (2020). An overview on the biosynthesis and metabolic regulation of monacolin K/lovastatin. Food Funct. 11, 5738-5748. doi: 10.1039/D0FO00691B
Zhang, Z., Ali, Z., Khan, S. I., and Khan, I. A. (2016). Cytotoxic monacolins from red yeast rice, a Chinese medicine and food. Food Chem. 202, 262-268. doi: 10.1016/j.foodchem.2015.12.039

Zhen, Z., Xiong, X., Liu, Y., Zhang, J., Wang, S., Li, L., et al. (2019). $\mathrm{NaCl}$ inhibits citrinin and stimulates Monascus pigments and monacolin K production. Toxins 11:118. doi: 10.3390/toxins110 20118

Zhu, L., Han, Q. B., Ho, A., Hsiao, W. L., and Jiang, Z. H. (2013). Characterization and simultaneous determination of immunosuppressive decalins in red yeast rice by ultra-high-performance liquid chromatography hyphenated with mass spectrometry. J. Chromatogr. A 1303, 54-61. doi: 10.1016/j.chroma.2013. 06.045

Zhu, L., Yau, L. F., Lu, J. G., Zhu, G. Y., Wang, J. R., Han, Q. B., et al. (2012). Cytotoxic dehydromonacolins from red yeast rice. J. Agr. Food Chem. 60, 934-939. doi: 10.1021/jf203579f

Conflict of Interest: The authors declare that the research was conducted in the absence of any commercial or financial relationships that could be construed as a potential conflict of interest.

Copyright (c) 2020 Yanli and Xiang. This is an open-access article distributed under the terms of the Creative Commons Attribution License (CC BY). The use, distribution or reproduction in other forums is permitted, provided the original author(s) and the copyright owner(s) are credited and that the original publication in this journal is cited, in accordance with accepted academic practice. No use, distribution or reproduction is permitted which does not comply with these terms. 